\title{
Global Environmental Risks
}

\author{
by \\ Graciela Chichilnisky, Columbia University \\ Geoffrey Heal, Columbia Business School \\ January 1993
}

Discussion Paper Series No. 645

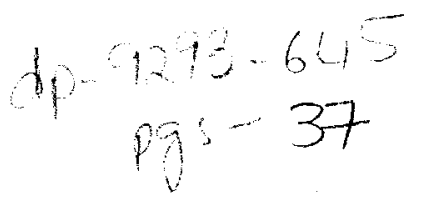




\title{
Global Environmental Risks
}

\author{
G. Chichilnisky* \\ Columbia University \\ G.M. Heal ${ }^{\dagger}$ \\ Columbia Business School
}

January 1993

\begin{abstract}
We study the risks associated with the prospect of global climate change, and review the mechanisms available for their efficient allocation in market economies. Risks in this field are typically unknown and often unknowable ex ante; their probabilities are endogenous and determined by economic actions; they have both collective and individual components, and they are about processes that may be irreversible.

The theory of how to allocate such risks is still being developed, but a certain amount is known about insurance with unknown risks and about uncertainty and irreversibility. We indicate what is known and set out its policy implications, and provide a challenging but realistic research agenda.

We show that existing theories provide a framework for evaluating policies for mitigating global climate change. How much a society should pay to mitigate global change depends on a society's discount rate, degree of risk aversion, and assessment of the relevant probabilities. As these may differ from society to society, what societies are willing to pay will vary. These differences may provide a basis for international trade in global climate risks. We argue that there is a real value to international institutional arrangements and financial markets that encourage countries to back words by deeds by making them liable to buy and sell risks associated with global climate change at the prices that their economic policies implicitly put on these risks.
\end{abstract}

\section{Contents}

1 Pervasive Uncertainty . . . . . . . . . . . . . . . . 2

2 The Nature of Environmental Uncertainty . . . . . . . . . . . . 3

*To appear in Journal of Economic Perspectives.

t Financial support from the Fondazione Eni Enrico Mattei is gratefully acknowledged by both authors, as are valuable comments on the papers on which this is based from Ken Arrow, Andrea Beltratti and Bob Solow. 
3 Risk -Allocation in a General Equilibrium Framework . . . . . . . . 5 5

4 Unknown Risks . . . . . . . . . . . . . . . . . 6

4.1 Ignorance and Uncertainty . . . . . . . . . . . . . . . 7

4.2 An Institutional Framework for Unknown Risks . . . . . . . . . . . 10

4.3 Trading Risks . . . . . . . . . . . . . . . . . . . . 11

5 Reducing the Risk . . . . . . . . . . . . . . . . . 12

5.1 Valuing a Reduction in Risk . . . . . . . . . . . . . . 13

5.2 Global Climate as a Public Good . . . . . . . . . . . . . 16

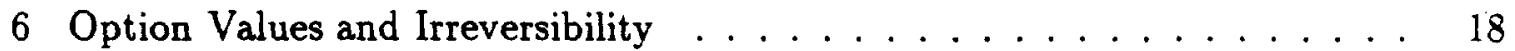

6.1 Waiting for Information . . . . . . . . . . . . . . 19

6.2 Option Values . . . . . . . . . . . . . . . . . 21

6.3 Uncertainty about Future Generations . . . . . . . . . . . . 22

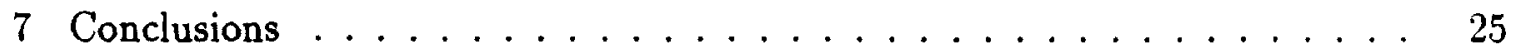

\section{Pervasive Uncertainty}

A striking aspect of global climate change and the greenhouse effect, is the extent and depth of the uncertainty about most important aspects of the problem. In particular,

1. There is uncertainty about the basic scientific relationships underlying this phenomenon, such as the relationship between gaseous emissions and global mean temperature, and the relationship between global mean temperature and climate. Clearly it is climate, a multi-dimensional variable encompassing wind patterns, humidity, rain patterns and storm patterns, and not just temperature, that may matter from a socio-economic perspective.

2. Future emissions of greenhouse gases are uncertain, and are endogenous in that they can be influenced both by climate changes and by policy measures.

3. From the perspective of applied welfare economics, there are uncomfortable questions about the appropriateness of our usual cost-benefit procedures for issues so far-reaching both into the future and throughout the economy.

Item 1 on this list concerns scientific uncertainties: items 2 and 3 have economic sources, in one case in the functioning of the economy, in the other case in the structure of economic analysis. Resolution of all of the relevant uncertainties can only be achieved by interdisciplinary research, an issue to which we shall return several times. Schematically, we can represent these links as in Figure 1. Every link in this chain is poorly understood and uncertain.

Figure 1 here.

Economics can tell us how to allocate resources efficiently under uncertainty, given certain standard assumptions. Unfortunately, however, the above items exceed the 
scope of these standard assumptions. They pose questions about the treatment of uncertainty which are particularly interesting, but also particularly difficult. Most of this article is addressed to them, and to the conclusions one can reach. While these conclusions are far from complete, they are certainly sufficient to suggest some innovative institutional developments in the field of global risk trading ${ }^{1}$.

\section{The Nature of Environmental Uncertainty}

There are two standard policy responses to risk. One is mitigation, i.e., taking steps to reduce one's exposure to adverse outcomes. The other is insurance, i.e., entering into contracts to ensure compensation in the event of adverse outcomes. Both are relevant in the context of global climate change. One can think of them as equivalent respectively to prevention and cure in the medical field.

Mitigation means taking steps to reduce the probability of change, or the expected impact of change. If steps are taken to reduce the probability of change, then the probabilities of change become endogenous, determined by policy measures. This contrasts with most of our models of resource-allocation under uncertainty, in which probabilities are exogenous.

Insurance does nothing to reduce the chances of damage due to climate change. It only arranges for those who are adversely affected, to receive compensation. The provision of insurance is a major sector of the economy, involving both the insurance industry and large parts of the securities industry. Can the existing and very active private sector organizations provide individuals and firms at risk from climate change with adequate insurance cover? If not, why not? What changes in market institutions might be appropriate in this case?

This paper is about these and related questions. In attempting to answer them, we deal with many different aspects of the theory of risk-bearing. Key themes which recur in our analysis are:

1. Most of the risks that we face are unknown, and indeed in a statistical sense are unknowable. In all likelihood we will never have data that will enable us to determine the probability of global climate change in the relative frequency sense. Most of the events against which we might wish to insure, are inherently unique. Even in a purely subjective sense, it has to be recognized that the probability of a particular global climate change is practically unknowable. We have to face the question of how to insure against unknown risks.

\footnotetext{
${ }^{1}$ Managing climate risks is not a new activity. In medieval England, a peasant farmer's land was broken into many small parcels spread all over the village. Economic historians interpret this as a way of hedging climate risk. Land in different locations would be affected differently by droughts, floods, frosts, etc. Hence by spreading land holdings over different locations, farmers diversified climate risk.
} 


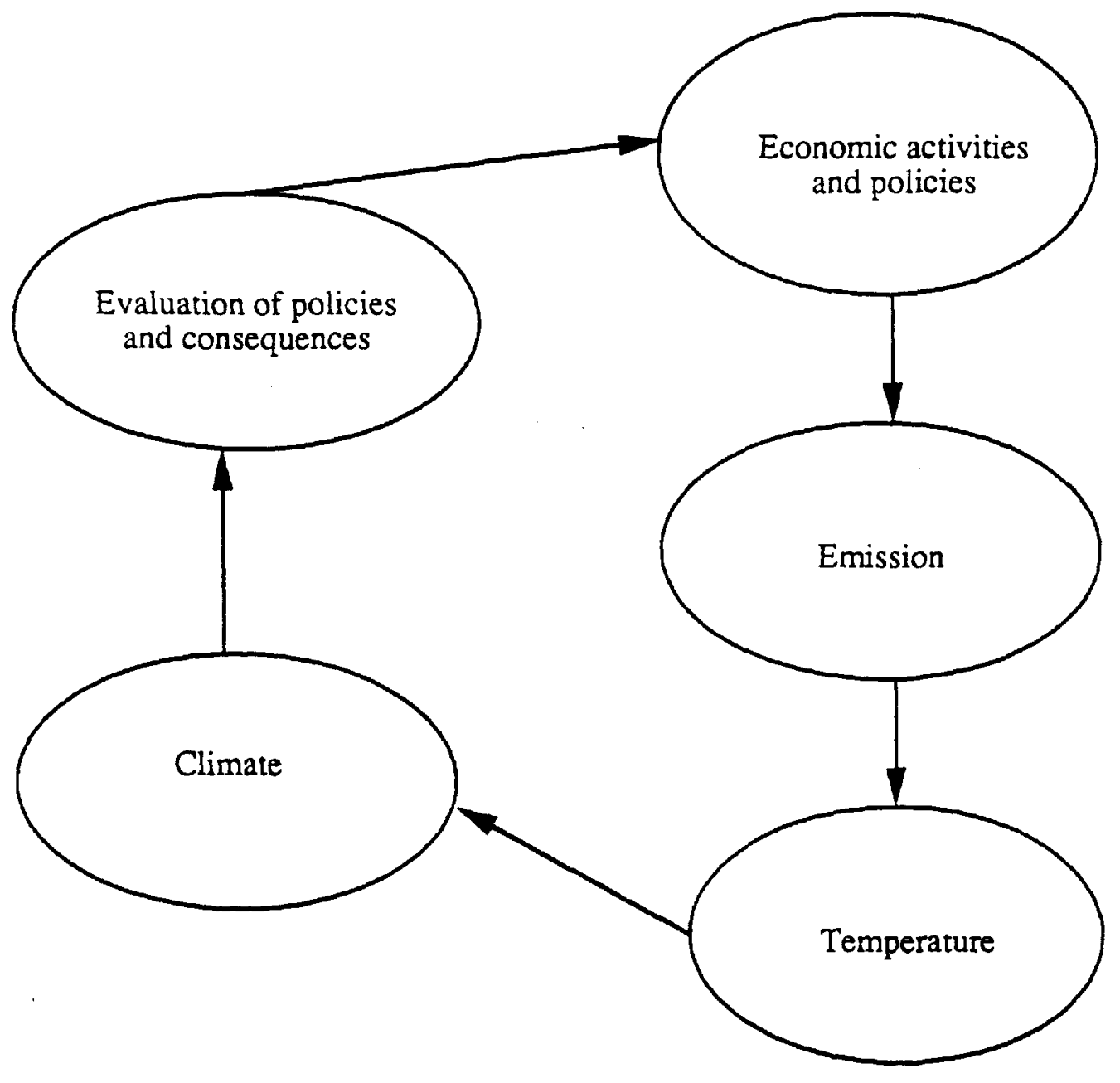

Figure 1: uncertainty is ubiquitous 
2. The probabilities of the risks that we face are affected by our actions. This is not incompatible with these probabilities being unknown: we may know that reducing the emission of carbon dioxide reduces the chances of a certain type of climate change, without knowing the details of the reduction. However, from an analytical perspective, this introduces a complication: the risks are endogenous. There is a generalized problem of moral hazard in such cases.

3. The risks associated with climate change, are typically collective or correlated risks. Climate changes will affect large numbers of people in the same way: Insurance markets, of course, work best for large numbers of small statistically independent risks. We thus have to ask what types of markets work best with collective risks.

4. Many major economic decisions, and their consequences, are irreversible. Climate changes, the melting of ice caps, desertification, species extinction, are all processes not reversible on interesting time scales.

In summary, we are dealing with risks that are poorly understood, endogenous, collective and irreversible. The theory of how to deal with these, is currently being developed. In the following sections, we summarize what is currently understood, and how our knowledge needs to be extended. In the process we provide a challenging but realistic research agenda.

In the next section we review briefly the theory of resource allocation under uncertainty in a general equilibrium framework, and then in section 4 we set out what is known about the theory of resource allocation in the face of risks whose probabilities are unknown. We argue that insurance cover can be provided for risks that are unknown, but that this requires the simultaneous use of securities markets in conjunction with insurance markets. This insurance can be implemented through a combination of markets for securities whose payoffs depend on which model of global warming is correct, and mutual insurance or compensation agreements between regions. These agreements are contingent on which model of global warming is correct. The markets for securities whose payoffs depend on the correct model of global warming, provide a mechanism for hedging uncertainty about the extent of global warming. The mutual insurance contracts then give insurance appropriate to the realized extent of global warming We then set out the institutional implications of this theory, and discuss the benefits associated with international trading of securities whose payoffs depend on climate risk.

In section 5 we provide a framework for evaluating policies that offer a chance of mitigating global climate change. How much a society should pay to mitigate global change, will be shown to depend on its discount rate and degree of risk aversion, and on its assessment of the relevant probabilities. As these may differ from society to society, what societies are willing to pay will vary. These differences may provide a basis for international trade in global climate risks. We argue that there is a real value 
to institutions that encourage countries to "put their money where their mouths are" by making them liable to buy and sell risks associated with global climate change at the prices that their policies implicitly put on these risks. Section 5 also contains an analysis of the extent to which climate and the risk of climate change can be viewed as public goods.

The last section, section 6 , is devoted to the issue of irreversibility and uncertainty. Clearly climate changes and associated environmental changes, such as the melting of ice caps, desertification, and species extinction, are irreversible. There is a presumption that decisions with irreversible consequences have to be made with particular care and according to different rules from those that are reversible. We explore this is section 6, providing some simple examples of situations where irreversibility is important and giving general conditions under which this is true.

\section{Risk - Allocation in a General Equilibrium Frame- work}

Our standard model of risk-allocation in a market economy is that of Arrow [1] and Debreu [17]. In this framework, there is a set of exogenous "states of the nature", following the framework of de Finetti [18] and Savage [33], whose values are random and represent the sources of uncertainty. Classically one thinks of events such as earthquakes and meteor strikes. Agents in the economy are allowed to trade commodities contingent on the values of these exogenous variables: these are called "state-contingent commodities". With a complete set of markets for state-contingent commodities, the first theorem of welfare economics holds for economies under uncertainty, so that an ex-ante Pareto efficient allocation of resources can be attained by a competitive economy with uncertainty about exogenous variables.

Arrow [1] showed that efficiency can in fact be attained by the use of a mixture of securities markets and spot markets, so that a complete set of contingent commodity markets is not required. This observation provides a natural and important role for securities markets in the allocation of risk-bearing, and gives a more familiar and plausible structure to the set of markets needed for efficiency under uncertainty. The securities used in this construction are contracts that pay one unit if and only if a particular uncertain exogenous variable assumes a specified value, i.e., if and only if a particular state occurs.

Under certain conditions, an alternative to the Arrow-Debreu model of risk bearing via contingent commodity markets, is the use of insurance markets. Here insurance companies act as intermediaries and pool large numbers of similar but statistically independent risks. In so doing they are able via aggregation and the use of the law of large numbers to neutralize the risks faced by large numbers of similar individuals. The main references on this are Arrow and Lind [3] and Malinvaud [29], [28].

In both of these approaches to resource-allocation under uncertainty (the approach 
via trading state-contingent commodities or securities, and the approach via insurance), it is assumed that agents know, or believe that they know, the probabilities of the states of nature ${ }^{2}$. In the context of environmental uncertainty, this is clearly a poor assumption. Obviously we do not know the risks associated with global climate change, nor are we likely to for many years. We are well aware of our ignorance. There are many environmental risks where we have enough knowledge to be concerned at the possibility of negative consequences, but not enough knowledge to claim that we know the probabilities of different outcomes. The next section of the paper will review what we know about risk-allocation when risks are unknown.

Another shortcoming of the insurance approach to risk-bearing in the context of global climate risks, and indeed in the context of environmental risks more generally, is that environmental risks are typically not independent risks or individual risks: they tend to be correlated across sets of agents. If one member of a community is exposed to polychlorinated biphenyls in ground water, then so presumably are thousands of others: if one location is exposed to risks associated with climate change, then so presumably are all those nearby. Risks of this type are called collective as opposed to individual risks. Chichilnisky and Wu [12] give a two-dimensional classification of risks, in terms of and exogenous versus endogenous and collective versus individual.

\section{Table 1 here}

Exogenous uncertainty arises from events whose probabilities are determined outside the economic system (earthquakes, meteor strikes), whereas endogenous is that arising from uncertainty about the values of variables determined within the system. Most theories of resource-allocation under uncertainty concern exogenous uncertainty. Collective uncertainty is that which affects everyone, whereas private uncertainty affects one person only. In reality there is a complete spectrum of possibilities between these two types.

\section{Unknown Risks}

In this section we review the theory of resource allocation in the face of unknown risks, and consider its implications for the development of institutions that can insure against global climate risk. Section 4.1 summarizes the theory, and sections 4.2 and 4.3 develop its institutional implications.

\footnotetext{
'In Arrow's paper on the role of securities markets, this is quite explicit, as it is in Malinvaud's formalizations. Debreu's model is less explicit on this matter, but his assumption that agents have well-defined preferences implies that agents either know or behave as if they know (i.e., are subjectively certain about) the probabilities of different states.
} 


\begin{tabular}{|l|l|l|}
\hline Collective & Individual & \\
\hline $\begin{array}{l}\text { Meteor } \\
\text { strike }\end{array}$ & $\begin{array}{l}\text { House } \\
\text { burns }\end{array}$ & Exogenous \\
\hline $\begin{array}{l}\text { Financial } \\
\text { crisis }\end{array}$ & $\begin{array}{l}\text { Loss of } \\
\text { job }\end{array}$ & Endogenous \\
\hline
\end{tabular}

Table 1 


\subsection{Ignorance and Uncertainty}

Consider an economy in which agents face risks with unknown probabilities. Such risks could derive from the impact of global climate change on income levels, or from the effects on health of ozone depletion, of acid rain, or of air pollution. The risks might be not just unknown but also unknowable, in the sense that we cannot reasonably imagine repetition of the harmful events a number of times sufficient to permit estimation of probabilities. Clearly this is the case with ozone depletion or global warming, which are events that will only happen once if at all. In such cases, opinions may differ widely about the magnitudes of the risks to which individuals are exposed. What market structure would suffice to assure efficient allocations in this situation?

Chichilnisky and Heal [11] formalize this question in a simple general equilibrium model. Each agent faces the risk of being in one of several states (e.g. healthy or sick for an individual, productive or unproductive for a farm). Agents have different endowments in each state. Risks are unknown, in the sense that no-one knows the true frequency distribution of affected agents in the population. A probability is assigned to each possible frequency distribution of affected individuals within the population. These probabilities form a distribution that assigns likelihoods to alternative frequency distributions. A typical one might state for example that there is a $10 \%$ chance that $90 \%$ of the population will be affected by global warming, a $25 \%$ chance that $50 \%$ of the population will be affected, etc. The distribution over distributions may be different from individual to individual. So not only are risks unknown: there may be a divergence of opinions about them.

We have therefore two levels of uncertainty. The first level of uncertainty is collective: what is the distribution of affected agents in the economy? Will $90 \%$ be affected, or only $30 \%$ ? The second level of uncertainty is individual: it is uncertainty about whether a given agent is affected or not. It devolves about questions such as: given that $90 \%$ of the population will be affected, will a particular agent be affected? Consider as illustrations the impact of depletion of the ozone layer on skin cancer, or of climate change on the livelihood of an agricultural community. There are widely differing opinions about these impacts, on which there is inadequate information. In some cases, the inherent uniqueness of the events concerned makes it impossible to develop a statistical basis for risk assessment. In these cases the two types or levels of uncertainty are:

firstly, uncertainty about the true relationship between ozone depletion and individual disease or between global climate change and agricultural productivity, and therefore about the impact of these phenomena on the population as a whole, and,

secondly, uncertainty about whether any given person or community will be affected.

Our ignorance of scientific processes (e.g., the relation between ozone depletion 
and skin cancer or between $\mathrm{CO}_{2}$ emission and climate change) causes the collective risk, by which we mean uncertainty about the distribution of affected agents in the population. Uncertainty about this distribution is central to the problem. When this is resolved we will still not know who is affected and who is not, but we will know the probabilities determining this. Then the problem is insurable.

We propose an institutional framework which uses two types of financial instruments, which are tailored to these two aspects of the problem, and which can lead to efficient allocation in the face of unknown risks. One type of instrument is a mutual insurance contract to deal with the risks faced by agents or communities contingent on each possible distribution of harmful effects worldwide. A mutual insurance contract is an agreement between parties subject independently to similar risks that those who are harmed will be compensated by those not so affected. An example is an agreement between a group of workers that if one is sick and unable to work, he or she will be compensated by the others for the income lost. In the present context, one could think of communities subject to the impact of climate change, with those positively affected compensating those negatively affected ${ }^{3}$. Making such a mutual insurance contract contingent on the distribution of harmful effects worldwide means that there is a different compensation agreement between the parties for each possible distribution of harmful effects. To know what compensation is due in any case, the parties have first to assess the distribution of harmful effects globally, and then on the basis of this they know which mutual insurance contract to apply and use the terms of that contract.

Secondly, we need Arrow securities to deal with the collective risk induced by ignorance, i.e. the uncertainty about the overall distribution of adverse effects in the economy. Arrow securities are usually defined as securities that pay one dollar if and only if a particular state of the world occurs. Here they pay one dollar if and only if a particular distribution (or correspondingly a particular theoretical model) is the true one, accurately describing the relationship between $\mathrm{CO}_{2}$ emission and climate. We treat each possible distribution of adverse affects as a distinct state, and use securities markets to enable parties to transfer wealth between these states. So one Arrow security is needed for each possible distribution of adverse effects worldwide, because to attain Pareto efficiency each separate state must be covered by a security. Depending on the state of knowledge, these distribution of adverse affects may be limited to a relatively small number of distributions, each described, for example, by an approximate percentage of agents affected in a particular way.

The following example will help to make this framework concrete. Consider a world of two countries 1 and 2 , in which the climate may be in one of two states $\alpha$ or $\beta$. There are two possible probability distributions over these two climate states. These distributions are called $A$ and $B$, with distribution $A$ giving a probability of 0.1

\footnotetext{
${ }^{3}$ Although this arrangement is termed a "mutual insurance contract", it is quite a different arrangement from insurance in the normal sense, as analysed for example by Malinvaud [28]. There is no use of the law of large numbers here to annul the risk to the insurer.
} 
to climate state $\alpha$ and a probability of 0.9 to climate state $\beta$. Distribution $B$ give the reverse probabilities, i.e., it gives probability 0.9 to climate state $\alpha$ and probability 0.1 to climate state $\beta$. The endowments of the two countries depend on the climate state, and are as follows: $\omega_{1}(\alpha)$ is country l's endowment vector if the climate is in state $\alpha$, and $\omega_{2}(\alpha)$ is the corresponding endowment for country 2 . Similarly, endowments in climate state $\beta$ are given by $\omega_{1}(\beta)$ and $\omega_{2}(\beta)$ respectively. Endowments satisfy the following inequalities:

$$
\begin{aligned}
& \omega_{1}(\alpha)>\omega_{2}(\alpha) \\
& \omega_{1}(\beta)<\omega_{2}(\beta)
\end{aligned}
$$

so that country 1 is relatively better off in state $\alpha$ and country 2 in state $\beta$. This data is summarized in Table 2.

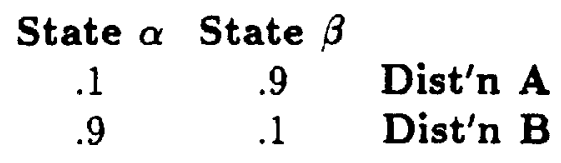

Table 2

Our results establish that to reach an efficient allocation of risks we need certain financial instruments. In particular, we need two Arrow securities. One, $S_{A}$, pays $\$ 1$ if and only if the probability distribution over states of the climate is $A$. The other, $S_{B}$, pays $\$ 1$ if and only if the probability distribution over states of the climate is $B$. Countries can spread the risk arising from not knowing which is the true distribution over states of the climate by trading these two securities. In addition they make mutual insurance contracts conditional on states of the climate. Such a contract could take the following form. If the distribution over climate states is $A$ (distribution $A$ gives probability 0.1 to climate state $\alpha$ and probability 0.9 to climate state $\beta$ ) then country 1 makes a transfer $\Delta_{1,2}^{\alpha}$ to country 2 if the state of the climate is $\alpha$, and country 2 makes a transfer $\Delta_{2,1}^{\beta}$ to country 1 if the climate state is $\beta$. These transfers satisfy

$$
0.1 \Delta_{1,2}^{\alpha}+0.9 \Delta_{2,1}^{\beta}=0
$$

so that the expected transfer is zero and the mutual insurance contract is actuarially fair.

To summarize the argument:

given a global distribution of the impacts of climate change, the risks we face are known. Hence given such a distribution, we can use mutual insurance contracts to allocate risks. This means having a different contract for each possible distribution of impacts. Agents are then left only with risk about the distribution that will occur. This risk is allocated through markets for securities that pay off depending on the distribution. These ideas are shown schematically in figure 2 .

Figure 2 here 


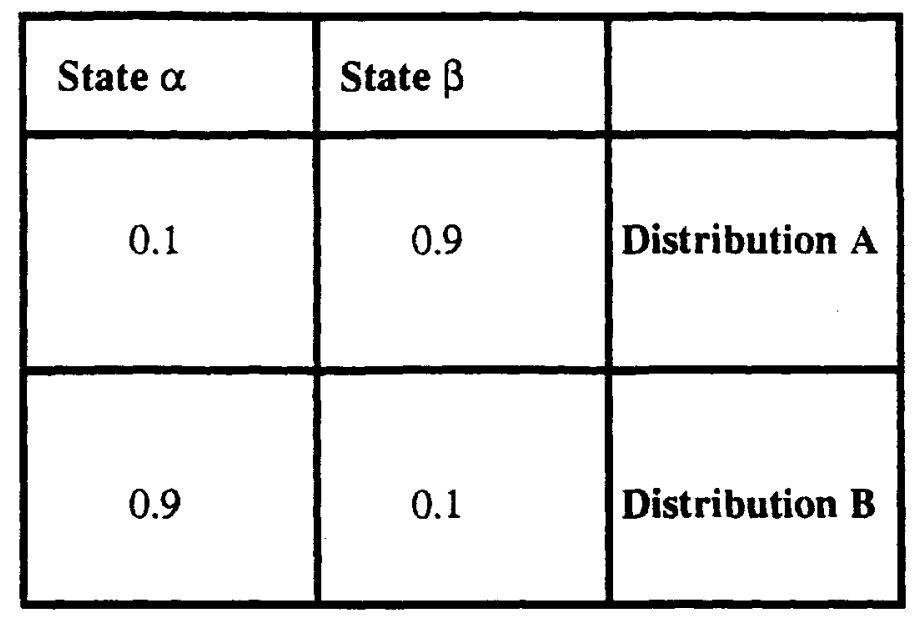

Table 2 
Two alternative distributions A \& B over possible climate states.

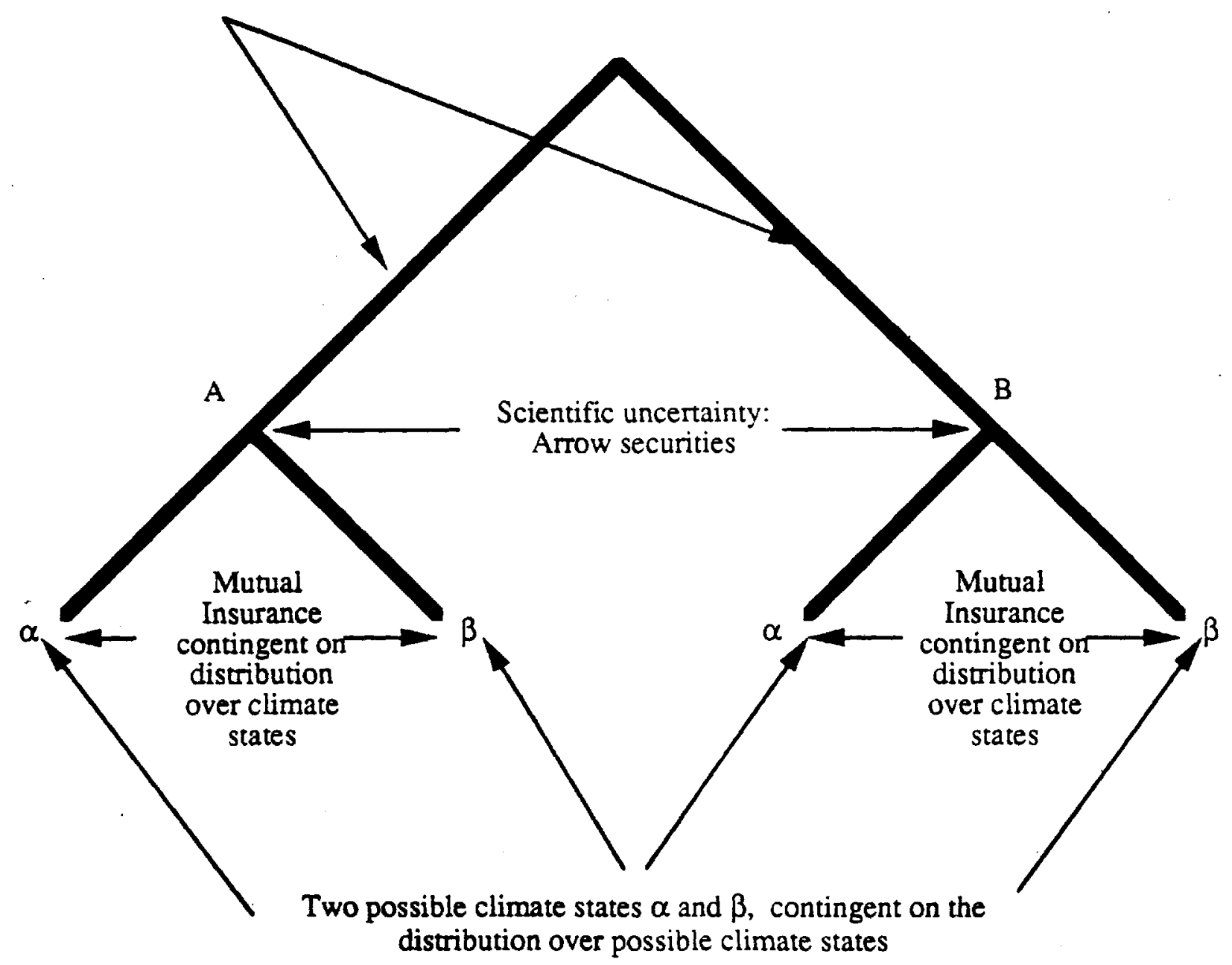

Figure 2: the realtionship between scientific uncertainty and climate uncertainty contingent on the true distribution over possible climate models, and the use of securities and mutual insurance contracts. 
There are two features of the results which are of general interest. One is the development of a framework for achieving efficient allocations in the face of individual risks whose probabilities are unknown. Given rapid changes in technology with potentially far-reaching environmental impacts and health effects, the problem of providing insurance against unknown risks is particularly important (Heal [19]). It is a matter of very active concern in the insurance industry.

The second interesting feature is the way a combination of securities markets and insurance markets can be used to provide a relatively simple institutional structure for dealing with unknown risks. The point here is that unknown risks can be resolved into a component that is truly collective and one that is not. The collective component refers to the distribution of certain conditions globally, and the other component, to the probability of a particular group being affected. Securities markets are used to insure against the global component ${ }^{4}$, and insurance contracts are used for the remainder of the risk. This is illustrated in Figure 2. The use of securities markets and insurance markets together has not previously been studied (except for Cass, Chichilnisky and $\mathrm{Wu}[10])^{5}$.

\subsection{An Institutional Framework for Unknown Risks}

Our analysis suggests that although the risks associated with global climate change are unknown, there is nevertheless an institutional framework, involving the use of financial markets, within which insurance can be provided. It involves:

1. Identifying the set of possible descriptions of the risk..

2. Introducing securities whose payoff depends on which description of the risk is correct. This amounts to allowing agents to bet on which model of the risk is right.

3. Establishing compensation agreements between harmed and unharmed regions that depend on which description of the risk turns out to be correct.

In Step 1, we have to identify the set of all possible relationships between $\mathrm{CO}_{2}$ emission and climate change, and parameterize this in such a way that it can be represented by a modest number of alternatives. Step 2 amounts, as noted, to allowing agents to bet on the odds of alternative characterizations of the risk being correct. Step 3 requires that agents enter into mutual compensation agreements specifying transfers to be made between those harmed and those unharmed or indeed benefited

\footnotetext{
${ }^{4}$ It is important that the Arrow securities be properly defined. For this we need to know the set of possible $\mathrm{CO}_{2}$-emission - climate relationships, with each defining a statistical state. Chichilnisky and Wu (12) show that if this is not the case, then there is a positive probability of default on the Arrow securities.

${ }^{5}$ Given the current interest in the insurance industry about its relationship with the securities industry, a model of value-added interaction between the two is very timely.
} 
by global climate change, with the details of the agreements depending in principle on which description of the risk is accurate.

Of these three steps, clearly the second two are feasible. Betting on which of several alternative descriptions of the way the world works is correct, is in effect what one does when choosing one research strategy over another: corporations, individuals and governments all do this regularly. A securities market in which there are traded securities of high-technology firms pursuing different research strategies towards the same goal is a financial market in which these bets are made. Likewise, mutual insurance contracts or mutual compensation agreements are already part of our institutional framework. In fact, they date back to the nineteenth century, and were the foundations of many current insurance companies and trade unions. The only really challenging part of our proposal, is the requirement to parameterize the set of possible relationships between $\mathrm{CO}_{2}$ emission and climate change. However, unless we can do this, it is difficult to see how there can be rational decision-making in this area.

This highlights a key field for interdisciplinary research: identifying the set of possible $\mathrm{CO}_{2}$ emission-climate relationships, that is, agreeing on a description of all of the possibilities facing us. If we were working in a Savage framework, this would amount to identifying the set of all possible states. This is a matter to which little attention is normally given: usually one assumes the set of states to be known. Note that we are not asking for an agreed set of probabilities over the set of possible emission-climate relationships, but just an agreed description of the set. Once we have this, we at least know what we do not know.

\subsection{Trading Risks}

An interesting aspect of the markets just described, is that they will provide a natural mechanism for reconciling differences between countries with respect to their assessments of the likelihood of important climate changes, and for testing the conviction behind publicly-stated positions ${ }^{6}$.

If for example the USA believes that the most likely outcomes are those involving little climate change, and the European Community believes otherwise, then through the market for securities whose payoffs depend on which description of climate change is correct, the USA will naturally sell insurance to the EC. The USA would wish to be a seller of securities which pay if climate change is serious, because of its belief that this event will not occur, and a buyer of securities that pay if it is not, because of its belief that this will be the outcome. The EC would be on the opposite sides of these markets.

International markets for the risks of climate change would also provide an ob-

\footnotetext{
${ }^{6}$ It is also worth remarking that the introduction of regulations limiting externalities or making explicit their costs often provide incentives for the development of technologies and activities that avoid or reduce the externalities.
} 
jective test of the seriousness with which countries adhere to their publicly-professed positions on the risk of climate change. It is for example possible that a country might publicly profess to a lack of concern about the risks of climate change, in spite of actually being concerned about these risks, in order to free ride on $\mathrm{CO}_{2}$ abatement policies introduced by others (these issues are discussed in detail in Heal [22] and the references cited there). The existence of markets for the risks of climate change would place such a country in a dilemma. Its true beliefs would incline it to sell securities paying off in the event of climate change not being serious, and buy those paying off if it is serious, whereas consistency with its public positions would require that it be on exactly the opposite sides of these markets. There would therefore be a cash cost to convincing and consistent misrepresentation of true beliefs. These cash costs could, as mentioned, offset some of the incentive to free ride on other countries' efforts to reduce greenhouse emissions.

It is also worth remarking in passing that the existence of international risk markets, together with the need to take part in mutual insurance schemes, would probably provide incentives to reduce $\mathrm{CO}_{2}$ emission. These markets would face countries directly with the financial consequences of greenhouse gas emission, and serve at least partly to internalize some of the externalities associated with these emissions.

\section{Reducing the Risk}

The fact that the risks of global climate change are unknown, is not the only demanding aspect of this problem. Another is that these risks are endogenous, in that they are clearly affected by our choices. In this section, we develop an implication of this, which is that we need to decide how much it is worth spending to reduce these risks. This is what we referred to as mitigation in the introduction. The extent of expenditure on mitigation determines the range of possible risks to which we are exposed. Insurance and risk-sharing activities then allocate these risks optimally between exposed parties. In the limit, it might be possible to reduce the risks to zero by energetic mitigation strategies, in which case there would of course be no need for insurance. In the previous section, all insurance contracts and securities contracts have to be interpreted as conditional on a given mitigation strategy.

In general, endogeneity of risks poses a problem for risk markets. The classic version of the moral hazard problem arises because the risks to which an agent is exposed, may depend on his or her actions, which in turn will be influenced by the terms on which insurance is available. This leads to arguments for coinsurance and deductibles (see Stiglitz [34]), and can also provide a motive for the introduction of new assets (see Chichilnisky and Wu [12]). Usually these problems are embedded in an asymmetric information framework, so that the insurer cannot fully asses the extent to which the insured has changed the probabilities by her or his actions. It seems to us that there is no issue of information asymmetry in the present context, so that moral hazard and principal-agent type problems are of no direct relevance. 
However, there are still delicate problems raised by the endogeneity of probabilities. The likelihood of climate change, has some of the aspects of a public good, just as does climate itself. Altering the probabilities of climate change by one's actions, produces externalities to others. Climate is both a state of the world, in the usual Savage sense, and in some measure a public good, and the probabilities of different climate values are affected by economic choices. We review the criteria for the optimal allocation of resources to reducing the risk of climate change, i.e., to endogenous control of probabilities, and then study briefly the extent to which climate and climatic risks have the characteristics of public goods.

\subsection{Valuing a Reduction in Risk}

What is it worth spending to reduce the probability of harmful climate change? Only if we can answer this question, can we judge properly proposals for carbon taxes, alternative energy strategies, and $\mathrm{CO}_{2}$-reduction protocols, all of which could involve very considerable costs, as indicated by Cline [15], Manne and Richels [30] and others. Here we shall summarize one approach to this problem, based on Heal [20] and [21]. This is a model that examines the extent to which the consumption of fossil fuels should be curtailed because this consumption increases the probability of a change in climate. It is based on the following assumptions:

1. The atmosphere may be in one of two states, one favorable to economic activity and one unfavorable.

2. The atmosphere transits stochastically from the favorable state to the unfavorable, and once there remains there for ever, i.e., atmospheric change is irreversible.

3. The probability of a transition from the favorable to the unfavorable state increase with the level of cumulative emissions from the use of fossil fuels.

The problem is summarized in figure three. Fossil fuels, capital equipment and the atmosphere are used to produce output, which may be consumed or reinvested to augment the capital stock. Production generates emissions, which affect the probability of a change in the state of the atmosphere.

\section{Figure 3 here}

In economic terms, the atmosphere is a resource that enters into the economy's production function. It may be in one of two states, either favorable or unfavorable to economic activity. These are denoted by $A_{f}$ and $A_{u}$ respectively. Initially the atmosphere is in the favorable state $A_{f}$ but may change stochastically to the unfavorable state, and once in this state will remain there forever. The probability of transition from the favorable to the unfavorable state is endogenous and depends on 


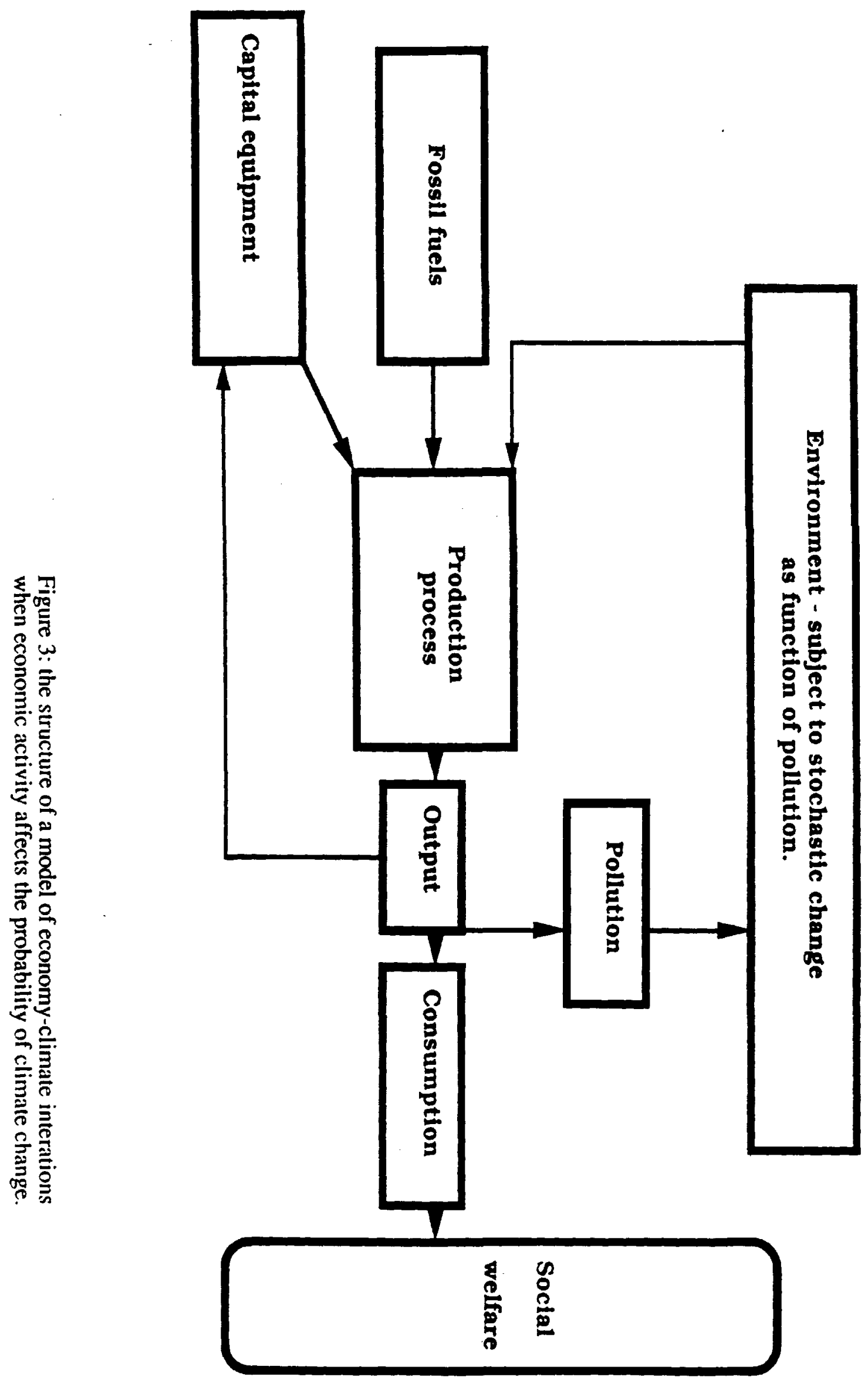


cumulative emissions into the atmosphere. The source of these emissions is the use of an exhaustible resource in production and the rate at which this is used at time $t$ is $r_{t}$. In addition to $r_{t}$ and $A$, the remaining input to production is the capital stock $k_{t}$. Letting $y$ denote total output production can be described by

$$
\begin{gathered}
y=f(k, r, A) \text { where } \\
A=A_{f} \text { or } A_{u} \text { and } f\left(k, r, A_{u}\right)<f\left(k, r, A_{f}\right) \text { for all } k \text { and } r .
\end{gathered}
$$

Output thus depends on capital, resources, and a cooperating climatic factor. The state of the atmosphere depends on cumulative resource use via cumulative emissions. Obviously the motivation for this is the emission of $\mathrm{CO}_{2}$ by the use of fossil fuels.

The rate of emission $e_{t}$ at time $t$ is assumed directly proportional to resource use at time $t$. The constant of proportionality can be set to one without any loss of generality, so that in fact we can identify $e_{t}$ and $r_{t}$. Cumulative resource use up to time $t$ is denoted $z_{t}$. The evolution of climate is as follows. There is a date $T$ such that $A=A_{f}, 0 \leq t \leq T, A=A_{u}, T \leq t \leq \infty$. Here $T$ is a random variable whose marginal density function $q$ has as its argument cumulative emission and depletion, $z_{t}$. It follows from this formulation that the probability that the date of the climate change $T$ occurs in any interval $\left[t_{1}, t_{2}\right]$ is

$$
\operatorname{Pr}\left\{T \in\left[t_{1}, t_{2}\right]\right\}=\int_{z_{t_{1}}}^{z_{t_{2}}} q\left(z_{t}\right) d t
$$

Therefore if $z_{t_{1}}=z_{t_{2}}$ and there is no emission in the interval $\left[t_{1}, t_{2}\right]$ then the probability of change in that interval is zero. Also when there is emission in an interval then the probability of change in that interval depends not only on the level of emissions in the interval but also on the cumulative emissions up to the start of the interval.

Total output may be divided between investment $\frac{d k}{d t}$ and consumption $c_{t}$. Consumption yields utility at a rate $u\left(c_{t}\right)$ and the objective is to maximize the expected present discounted utility of consumption. There is a constraint on the total amount of the resource that can be used, as this is exhaustible and only an amount $s_{0}$ is available:

$$
\int_{0}^{\infty} r_{t} d t \leq s_{0}
$$

The overall problem is thus:

$$
\begin{gathered}
\max E \int_{0}^{\infty} u\left(c_{t}\right) e^{-\delta t} d t \\
\text { subject to } \int_{0}^{\infty} r_{t} d t \leq s_{0} \\
\frac{d k}{d t}+c_{t}=f\left(k_{t}, r_{t}, A\right)
\end{gathered}
$$

The expectation here is over realizations of the stochastic process governing the climate change.

In this model it is possible to:

1. characterize optimal paths of consumption, capital accumulation and use of fossil fuel, and 
2. to compare these with the rates that are optimal in the absence of an atmospheric impact.

3. study the impact of changes in parameters such as the discount rate and degree of risk aversion.

4. isolate the key parameters in determining the optimal rate of use of fossil fuels.

One of the key trade-offs that emerges is the following. We can increase present well-being at the cost of a probabilistic reduction in future well-being. One can reduce the sharpness of this conflict by substitution of capital for energy, or (outside the scope of the formal model) by the replacement of fossil fuels by benign energy sources. The key parameters and functions in evaluating this trade-off between present utility and expected future utility are:

1. the discount rate

2. the degree of risk-aversion

3. the cost of climate change

4. the likelihood of climate change as a function of economic activity.

The last of these is a functional relationship rather than a parameter. Global change $R \& D$ leads us to a better understanding of this relationship. Of these four determinants, two, the discount rate and the degree of risk aversion, are strictly economic, and two require scientific input for their evaluation: these are the cost of climate change and the likelihood of climate change as a function of economic activity. It is worth stressing that proper economic analysis requires not just the likelihood of climate change as a result of one particular emission scenario, which is what most scientific analyses are providing, but rather a systematic evaluation of how the nature and likelihood of climate change varies with the pattern of economic activity. The study and characterization of this likelihood function is another important topic for interdisciplinary research in the area of climate change.

It is of course not surprising that what it is worth paying to reduce the risk of climate change depends inter alia on a society's degree of risk aversion and on its discount rate. However, this has an interesting and important implication, which is that even if there were complete agreement about all of the scientific aspects of the global change problem, there could still be disagreement about the appropriate policy responses. Because of the international externalities associated with climate, so that all countries "consume" the same climate, $\mathrm{CO}_{2}$ abatement policies only make sense if coordinated internationally (see Barrett [5], Carraro and Siniscalco [9], Heal [22]), and the fact that different countries need not agree on policy choices even if they agree on the scientific evaluation of the problem, could make such agreement 
difficult to obtain. One can in fact argue that stated differences in countries' positions with respect to the desirability of measures to restrict greenhouse gas emissions, are related to their discount rates and degrees of risk aversion. The US, for example, has been against any such measures, while Germany has been in favor: conventional wisdom has it that the financial and industrial community in the US has both a higher discount rate and a lower degree of risk aversion (greater willingness to take risks) than that in Germany. The differences in policy positions could, if this conventional wisdom is true, be attributed to differences in preferences rather than, or in addition to, different interpretations of the current scientific evidence. Figure 4 makes this point graphically.

Figure 4 here

The international coordination aspect of climate merits further analysis. The model of Heal [20] studies the extent to which economic activity should be modified because of its climatic impact. It does so however in a one-country model. This is useful because it highlights certain salient features and parameters which influence how a given country should analyze the problem, but it leaves out of consideration the fact that ultimately many countries or groups all interact in determining the overall level of emission abatement. This influence is a source of externalities. Each country will choose its optimal abatement strategy in the light of an assumption about the abatement levels of others (see for example Heal [22]), thus leading to a Nash equilibrium in abatement strategies. Because each country's analysis will neglect the effect of its abatement strategies on others, this equilibrium will typically be characterized by sub-optimal abatement levels. It has been widely argued that international abatement agreements have the character of Prisoners' Dilemma games, with non-participation a dominant strategy. However, there are conditions under which international abatement agreements are stable as decisions to participate are mutually reinforcing (Barrett [6], Carraro and Siniscalco [9], Heal [22]). Such effects can arise if there are fixed costs in abatement programs, or significant costs in the development of abatement technologies.

\subsection{Global Climate as a Public Good}

To what extent is global climate a public good? Clearly it has many of the key characteristics. In particular, the global climate or the weather system is the same for everyone. We all "consume" the same global climate. Likewise for the probability of climate change: whatever it is, it is the same for all of us. If global climate change becomes more likely for one, it becomes more likely all. So if the fact that the same level of a "good" is available to all makes it public, which is probably a consensus definition in public economics texts, then both global climate and global climatic risks are public goods ${ }^{7}$.

\footnotetext{
${ }^{7}$ Local climate or micro climate has many of the characteristics of a local public good.
} 


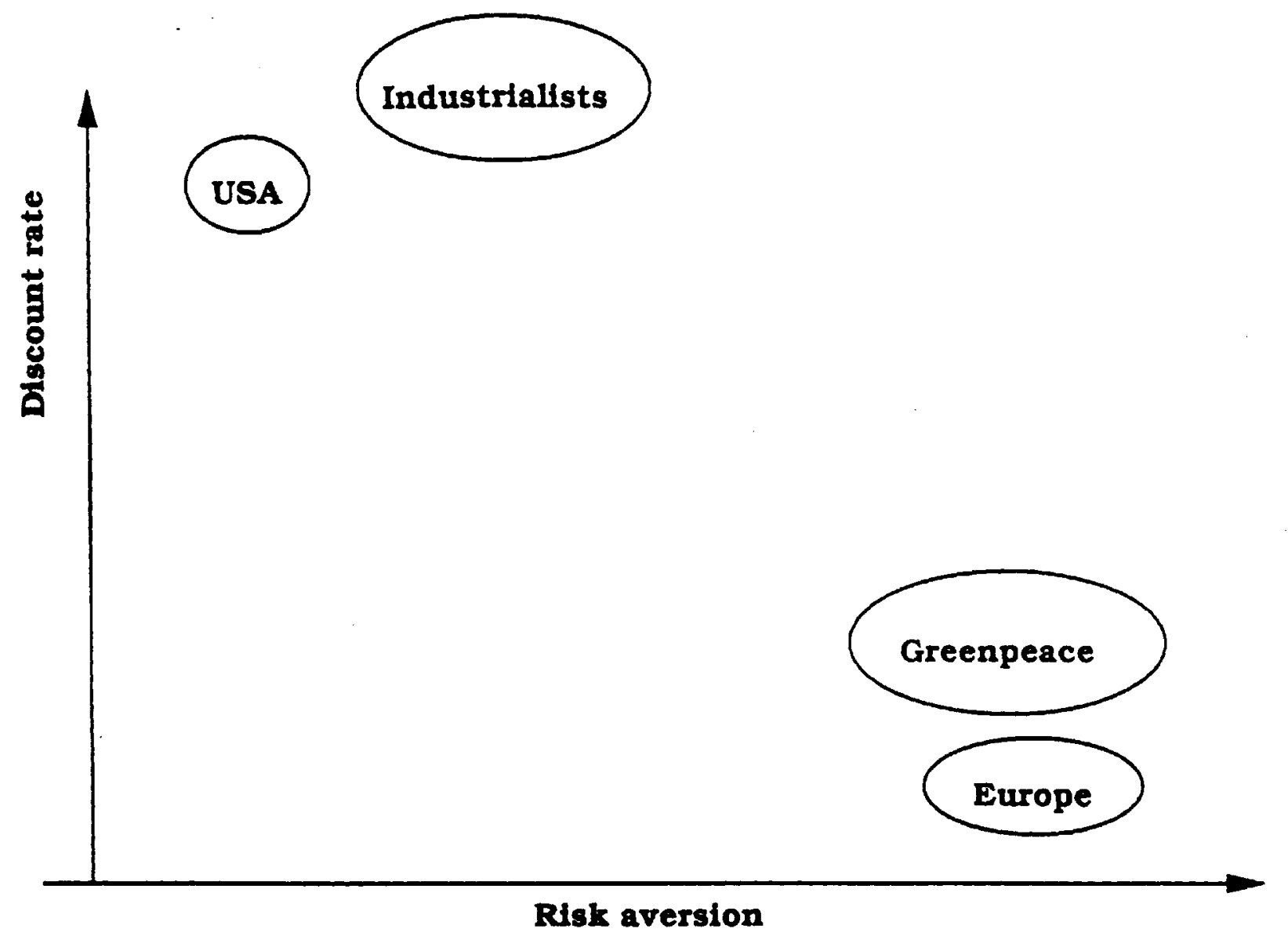

Figure 4 
However, there is one respect in which climate and associated risks do not fit the standard model of a public good, which is in the technology through which they are provided. The standard Bowen-Lindahl model of the optimal provision of a public good (see Atkinson and Stiglitz [4]) assumes that agents make independent consumption decisions, but that the good is provided by a central production facility. It is then straightforward to derive the classical first-order conditions stating that the sum of agents' marginal rates of substitution between the public good and a private good, must equal the marginal rate of transformation between the two in the central production facility. If we now try to think of a reduction in the risk of climate change as a public good, we see that it does not fit this model. There is no central production facility that transforms a consumption good into lower climate risk: this process is undertaken independently in each country via its emission controls. Hence the first order conditions for efficient provision of this "good" are different from the classical one, and more characteristic of a general externality.

To make the point very simply, consider a two country world in which the climate can be in one of two states, good $G$ or bad $B$. Countries are 1 and 2. Utility levels are $U_{i}\left(A_{i}, G\right)$ and $U_{i}\left(A_{i}, B\right)$ where $i$ may be 1 or $2, A_{i}$ is country $i$ 's expenditure on emission abatements (utility is decreasing in this), and the utility function is parameterized by the state of the climate. For all values of abatement expenditure $A_{i}$, utility is higher in state $G$ than in state $B$. The probability that the climate is in state $G$, is $p\left(A_{1}+A_{2}\right)$, which is increasing in its argument. So countries lose utility directly by abatement expenditure (it has a cost to them) but benefit from the higher chance of a favorable climate. Each country's abatement affects the other through the impact on the probability $p$. Climate is a public good in so far as it is either $G$ or $B$ for both countries, but each country makes an independent decision on how much to allocate to the production of a better climate by choosing $A_{i}$.

The first order conditions for a maximum of the sum of the two countries' expected utilities are just

$$
\left\{U_{i}^{\prime G} p+U_{i}^{\prime B}(1-p)\right\}+\sum_{i=1,2} p^{\prime}\left(U_{i}\left(A_{i}, G\right)-U_{i}\left(A_{i}, B\right)\right)=0
$$

where $U_{i}^{\prime G}=\frac{\partial U_{i}\left(A_{i}, G\right)}{\partial A_{i}}$ and $p^{\prime}=\frac{\partial p\left(A_{1}+A_{2}\right)}{\partial A_{i}}$. (1) has of course to hold for each country $i$. The second term here is the sum of the countries' marginal benefits from a reduction in the risk of climate change. It is the gain in utility between the good and bad states in each country, multiplied by the change in the probability of the good state. The first term, to which this has to be equated, is one country's marginal cost of risk reduction (remember that $U_{i}^{\prime G}$ is negative). This is therefore not the usual condition for the optimal provision of public goods, because it is requiring that the sum of the marginal benefits from controlling climate change be equated to the marginal cost on a country-by-country basis. It is a classic statement of the conditions for efficiency under externalities, with the benefit to the other country captured in the second term and providing the optimal level of a Pigouvian tax (on this see also Heal [21]). 
There is an additional reason why climate cannot be considered as an traditional public good, which is that climate is a "collective state" in the de Finetti-SavageArrow-Debreu sense. By this we mean that the value of the climate affects the values of the exogenous parameters in the model, such as preferences, endowments and technologies. Normally in a general equilibrium framework endowments, preferences and technologies are taken as parameters of the model that are state-dependent. Climate can of course affect of these: the weather can destroy endowments and affect production possibilities.

\section{Option Values and Irreversibility}

In valuing environmental resources such as current climate conditions, biodiversity, or complex ecological systems, the irreversibility of certain key decisions and events is central. Of course, a key aspect of these resources is that once they are altered, they cannot easily be restored to their current conditions, at least on an interesting timescale. Decisions not to preserve them, would be irreversible, and once implemented cannot be altered. The alteration or destruction of a unique asset of this type, has an awesome finality, and analysts have sought to capture this in a framework for cost-benefit analysis. This has led to the concept of "option value": preserving a unique asset in its present state, allows us the possibility of changing our minds later. Altering it irreversibly does not. Hence preserving it has to be credited with an "option value" because it keeps open to us the option of reconsidering our decision, whereas altering it leaves us no such option in the future. Preserving the asset allows us to retain a flexibility that is denied by altering it. Why is this valuable, and how can this fact be formalized? The answer is of course bound up with the nature of uncertainty facing decision-makers. Flexibility is only valuable if we do not know what the future will bring.

In this section we review two distinct formulations of this issue, one in which the returns to a preservation project are uncertain at present but will be revealed in the future, and one in which the preferences of future generations for environmental facilities are uncertain. The first framework is the one in which the issue of option values has traditionally been studied, and we provide an illustration of the argument in this case and illustrate the fact that one needs three conditions for an option value to exist - irreversibility, the acquisition of information with the passage of time, and a certain asymmetry of the underlying probability distribution which implies that on average the benefits from conservation will increase. Similar results are illustrated for the case of uncertainty about the preferences of future generations. Uncertainty and irreversibility alone do not suffice to create an option value: the expectation of a positive trend in benefits is needed. 


\subsection{Waiting for Information}

The option value of preserving an environmental or ecological asset has been explored in the context of uncertainty about the future benefits associated with its existence. Amongst the earliest studies of this issue were Weisbrod [35], Krutilla [27], Cichetti and Freeman [14], Arrow and Fisher [2] and Henry [24] [25]. The central issue in this work is that there are benefits that will accrue in the future from the preservation of a resource which are currently unknown. If the resource is preserved into the future, then in the future the decision about whether to preserve it can be reconsidered in the light of information then available about the benefits from its existence: if it is not preserved, then there is no chance of reconsideration when we have better information. It is shown that in this case conventional decision rules will underestimate the value of preserving the asset. The following example, taken from Dasgupta and Heal [16], illustrates the key point in a simple framework.

Consider two dates, $t=0$ and $t=1$. We have a fixed quantity, assumed equal to one, of an environmental asset. The benefit from preserving this at time $t=0$ is $b_{0}$. At time $t=1$ there are two possible states of nature $s_{1}$ and $s_{2}$. The state of nature is revealed at time $t=1$. If the state is $s_{1}$, the benefit of preserving the asset is $b_{1}$ : if $s_{2}$ is the state, the benefit is $b_{2}$. The probabilities of $s_{1}$ and $s_{2}$ are $p$ and $(1-p)$ respectively. Decisions about preservation are made at times $t=0$ and $t=1$. At $t=0$ a decision is made on how much of the asset to preserve until $t=1:$ at that date we may either conserve everything conserved at $t=0$, or conserve less. Given that destruction is irreversible, we cannot at $t=1$ conserve more than was conserved at $t=0$. Our options at $t=1$ are therefore constrained by the decision made at $t=0$. This data is summarized in figure 5 .

\section{Figure 5 here}

We shall compare two cases, the case already described where the decision made at time $t=0$ is irreversible, and an alternative case in which this decision can in fact be reversed. In this case the decision made at time $t=0$ no longer constrains the options available at time $t=1$. We look at this alternative case first, as it is simpler. Let $c_{0}$ be the amount of the resource conserved at time $t=0$, and $c_{1}$ and $c_{2}$ be the amounts conserved at time $t=1$ in states 1 and 2 respectively. The expected benefit from development (assuming a zero discount rate) is

$$
b_{0} c_{0}+p b_{1} c_{1}+(1-p) b_{2} c_{2}
$$

We have to choose $c_{0}, c_{1}$ and $c_{2}$ to maximize (2). We assume that:

$$
\begin{gathered}
b_{0}<0, b_{1}<0, b_{2}>0 \\
p b_{1}+(1-p) b_{2}>0
\end{gathered}
$$

Thus there is currently no benefit to preservation, nor is there any benefit in state 1 in the future. However, there is the possibility of state 2 in which there are positive 


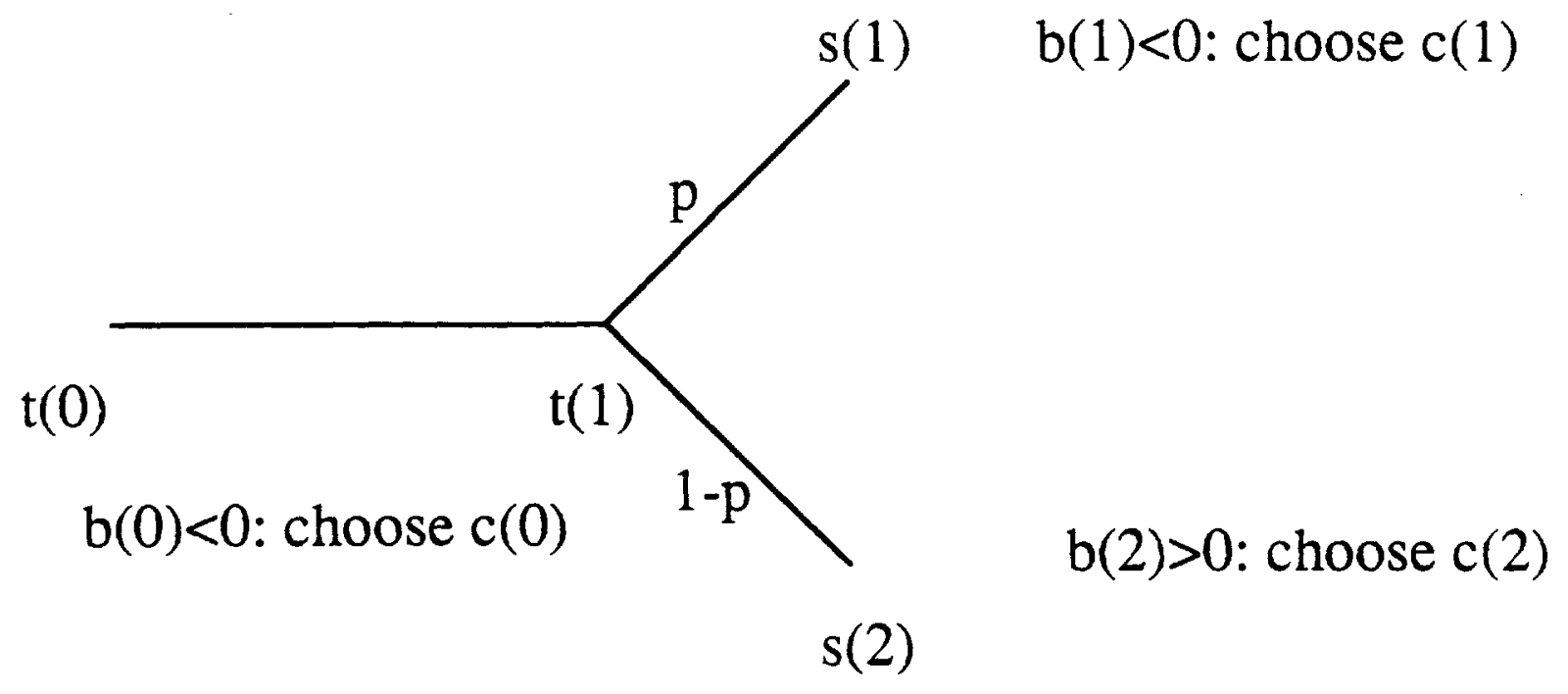

Figure 5 
benefits from preservation. Furthermore, the expected benefit from preservation at time $t=1$ is positive. Then if decisions are reversible, we preserve nothing at time $t=0$, i.e., we set $c_{0}=0$. Then at time $t=1$, we set $c_{1}=0$ and $c_{2}=1$. In the reversible case we can set $c_{2}=0$ because by assumption decisions made at $t=0$ are reversible.

Now consider the real case in which the decision at time $t=0$ cannot be reversed later. In this case the choice made at $t=0$ does constrain the choices open at $t=1$. We have to satisfy the constraint

$$
0 \leq c_{1}, c_{2} \leq c_{0} \leq 1
$$

This implies that what is conserved at time $t=1$ cannot exceed that which was conserved initially. In particular, if everything is destroyed in the first period, then we have no options in the second. What policies now maximize (2)? Clearly we will always set $c_{2}=c_{0}$ : that is, if in the second period the state of the world is one in which there are positive benefits to conservation, then we will conserve everything left to us by our earlier decisions. If however the state is unfavorable to conservation, then we will conserve nothing and set $c_{1}=0$. Hence the maximand (2) reduces to

$$
\left.\left\{b_{0}+\left(1-b_{2}\right) p\right)\right\} c_{0}+p b_{1} c_{1}=\left\{b_{0}+(1-p) b_{2}\right\} c_{0}
$$

and the initial conservation level is zero or one according as

$$
\left\{b_{0}+(1-p) b_{2}\right\}>0 \text { or }<0
$$

The inequality (5) has a simple interpretation: the left hand side is the expected payoff from conservation in the first period. It is the certain payoff in the first period plus the expected payoff from conservation in the second, given that if the state unfavorable to conservation occurs, then there will be no conservation in the second period. In other words, it is the expected payoff to conservation in period one, given that an optimal policy is followed subsequently. It is optimal to conserve in the first period if and only if this expected payoff is positive. Contrast this with the decision in the reversible case, in which we always chose $c_{0}=0$. These decisions are different if the expected payoff to conservation in the first period is positive.

As a final comparison, we look at the case in which the future benefits from conserving the resource are known with certainty to be equal to the expected value, which is $p b_{1}+(1-p) b_{2}$, and decisions are reversible, so that the choice of $c_{0}$ puts no constraints on the values of $c$. In this case the maximand is

$$
c_{0} b_{0}+c\left\{p b_{1}+(1-p) b_{2}\right\}
$$

where $c$ is the level of conservation in the future, which is now state-independent as there is only one state. Clearly we set $c=1$ and $c_{0}=0$ as $b_{0}<0$ and $p b_{1}+(1-p) b_{2}>0$ by assumption (see (3) above). Once again, there is never conservation in the initial period. 
The conclusion is that if a decision not to conserve cannot be reversed, then replacing uncertain benefits by their expected values and using normal project evaluation rules may lead to too little conservation. This is also true of pretending that the decision will be reversible. Conservation has an "option value" that is not recognized in the usual calculus.

\subsection{Option Values}

Note that the existence of an "option value" does not depend on risk aversion, as we assumed throughout the previous subsection that the maximand is the expected value of benefits. The variance of benefits thus has no impact on their evaluation. The key issues here are:

1. the irreversibility of the decision,

2. the fact that delaying a decision can let one take advantage of better information, together with

3. the asymmetry represented by the left hand side of (5) being positive. This condition of course implies that on average there will be benefits from conservation in the first period. We shall see in the next section that this type of condition plays a central role in many arguments about the optimality of delaying or postponing irreversible decisions.

Pindyck [32] considers a very similar example in the case of irreversible investment decisions, and shows that the option value of delaying an investment decision to take advantage of information that will become available in the future, can be computed using the formula used in finance for valuing an option to buy a stock. It is for this reason that we refer to option value rather than using the term quasi-option value now well-established in the environmental literature.

The analysis that we have just completed, has a very practical implication. Climate change is likely to be irreversible if it occurs. So in a cost-benefit analysis of preventing climate change (i.e., preserving the atmospheric environment), we should credit the benefits of preservation (preventing climate change) with an option value if we believe that the passage of time is likely to bring significant new information about the likelihood of climate change or about its consequences and that the expected payoffs satisfy a condition equivalent to (5) above. This is a condition that certainly cannot be ruled out: there is an active scientific research program on the climatic consequence of $\mathrm{CO}_{2}$ emission, and this will presumably at some time in the future resolve at least in part the uncertainties that we emphasized in the introduction. Probably the most thorough study of the costs and benefits of reducing climate change, is the book by Cline [15]. Although this study refers many times to the scientific uncertainties associated with predicting climate change, it at no point attributes 
an option value to preservation, i.e., to preventing climate change. This means that it may systematically underestimate the benefit-cost ratio of preservation of the atmosphere in its status quo. There is a related analysis in Manne and Richels [31] of the value of waiting for scientific information about the greenhouse effect. They consider two possibilities: one is acting strongly now to reduce the emission of greenhouse gases, and the other is taking limited action now and waiting until there is further scientific evidence before deciding whether to take stronger action. Taking major steps towards emission abatement now, amounts to conserving the atmospheric environment in its present state, and should again be credited with an option value. Some illustrative general calculations in Beltratti Chichilnisky and Heal [7] suggest that in some cases the impact $f$ recognizing an option value can be significant.

\subsection{Uncertainty about Future Generations}

There are several ways of generalizing or refining the concept of option value. A key consideration for many, seems to be the possibility that future generations will value environmental resources more highly than we do. If this is simply a statement that these resources will be scarcer, and so more valuable on the margin by the law of diminishing marginal utility, then this effect is captured in the usual approach to cost-benefit analysis (see Heal [23]).

It may, however, be a statement that future generations could have different preferences from us, and might value environmental assets differently. Because they might value them differently, and in particular value them more, we should, it is argued, attribute a value to leaving them the option of high consumption levels. This sounds close to the concept of option value set out above, and indeed it is, though there are some differences that are revealing. Below we study this problem, drawing heavily on results in Beltratti Chichilnisky and Heal (BCH) [7].

We shall use here a highly simplified version of the $\mathrm{BCH}$ model. Consider a two period world where there is a fixed total stock of a natural resource to be consumed in the two periods. The initial stock is known to be $s_{0}$. The amounts consumed in the first and second periods are $c_{1}$ and $c_{2}$ respectively: these must obviously satisfy $c_{1}+c_{2}=s_{0}$. As the stock is irreplaceable, anything that is consumed in the first period is not available in the second, so that consumption here is an irreversible depletion of the stock. The utility from period one consumption is $u\left(c_{1}\right)$, which is an increasing strictly concave function. The utility from second period consumption is unknown: it may be either $(1+\alpha) u\left(c_{2}\right)$ with probability $p$ or $(1-\beta) u\left(c_{2}\right)$ with probability $(1-p)$. Here $0<\alpha, \beta<1$. So there is a probability $p$ that the utility derived from future consumption will be "scaled up" by a factor $\alpha$, and a probability $(1-p)$ that it will be "scaled down" by a factor $\beta$. The situation is summarized in figure 6 .

Figure 6 here

Consider first as a benchmark the case in which there will be no change in preferences, so that we just have to pick $c_{1}$ and $c_{2}$ to maximize $u\left(c_{1}\right)+u\left(c_{2}\right)$ : the solution 


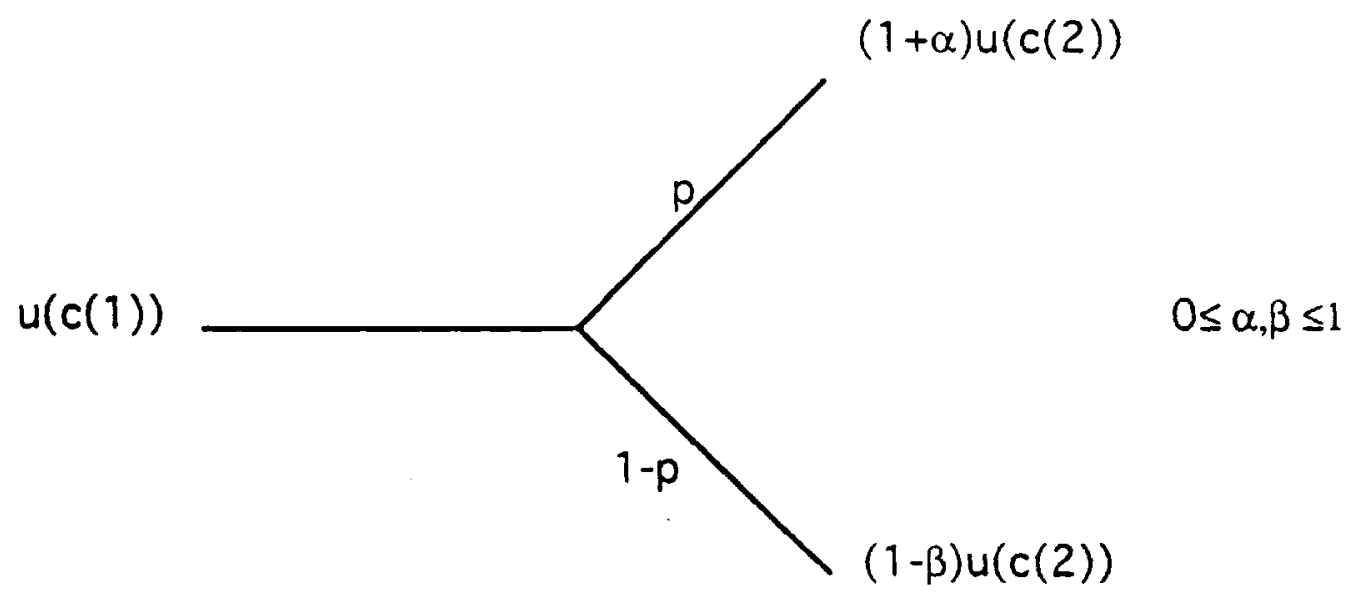

Figure 6 
is obviously to choose $c_{1}$ and $c_{2}$ so that the marginal utility of consumption is the same in both periods, i.e., $\frac{\partial u}{\partial c_{1}}=\frac{\partial u}{\partial c_{2}}$. Figure 7 shows this situation: the length of the horizontal axis is $s_{0}$, the initial stock of the resource. Consumption in the first period $c_{1}$ is measured to the right from the left hand origin and consumption in the second period to the left from the right hand origin. Marginal utility in each period is plotted, and the optimal levels of $c_{1}$ and $c_{2}$ are those at which the marginal utility curves cross. In the absence of discounting, and with utility functions the same in each period, these will of course be equal, as shown in figure 7 .

Now suppose that there is uncertainty about preferences in the second period. think of this as uncertainty about the preferences of a future generation. Also simplify matters by assuming that $\beta=0$, so that the only possible change in preferences is a "scaling up" of the utility of consumption. This corresponds to the case that we mentioned at the start of this section, namely the possibility of an increase in the appreciation that people have for the resource. Now we have to choose $c_{1}$ and $c_{2}$ to maximize the expectation of utility, which is

$$
u\left(c_{1}\right)+p(1+\alpha) u\left(c_{2}\right)+(1-p) u\left(c_{2}\right)
$$

The solution to this requires that

$$
\frac{\partial u}{\partial c_{1}}=\{p \alpha+1\} \frac{\partial u}{\partial c_{2}}
$$

so that marginal utility of consumption in the first period equals the expected marginal utility in the second. Clearly $\{p \alpha+1\}>1$, so that the expected marginal utility curve for second period consumption is now above the certain second period marginal utility curve in figure 7 , as shown.

Figure 7 here

The optimal first period consumption level is now lower than before, as a result of the possibility of a shift in future preferences towards the natural resource. Generally one can show (see [7]) that the amount of this reduction depends on the probability distribution governing the change in preferences, the discount rate and the degree of risk aversion. Does this reduction in period one consumption reflect an "option value $^{n}$ in the sense of the previous section?

To understand this, we have to consider the more general case that we posed initially. In this case, $\beta$ is no longer zero, and maximization of expected utility requires that

$$
\frac{\partial u}{\partial c_{1}}=\{p(1+\alpha)+(1-p)(1-\beta)\} \frac{\partial u}{\partial c_{2}}
$$

Now the period two expected utility curve may lie above or below the first period curve: it will be exactly the same as the first period curve, i.e., the curve in the absence of uncertainty, if and only if

$$
\{p(1+\alpha)+(1-p)(1-\beta)\}=1
$$




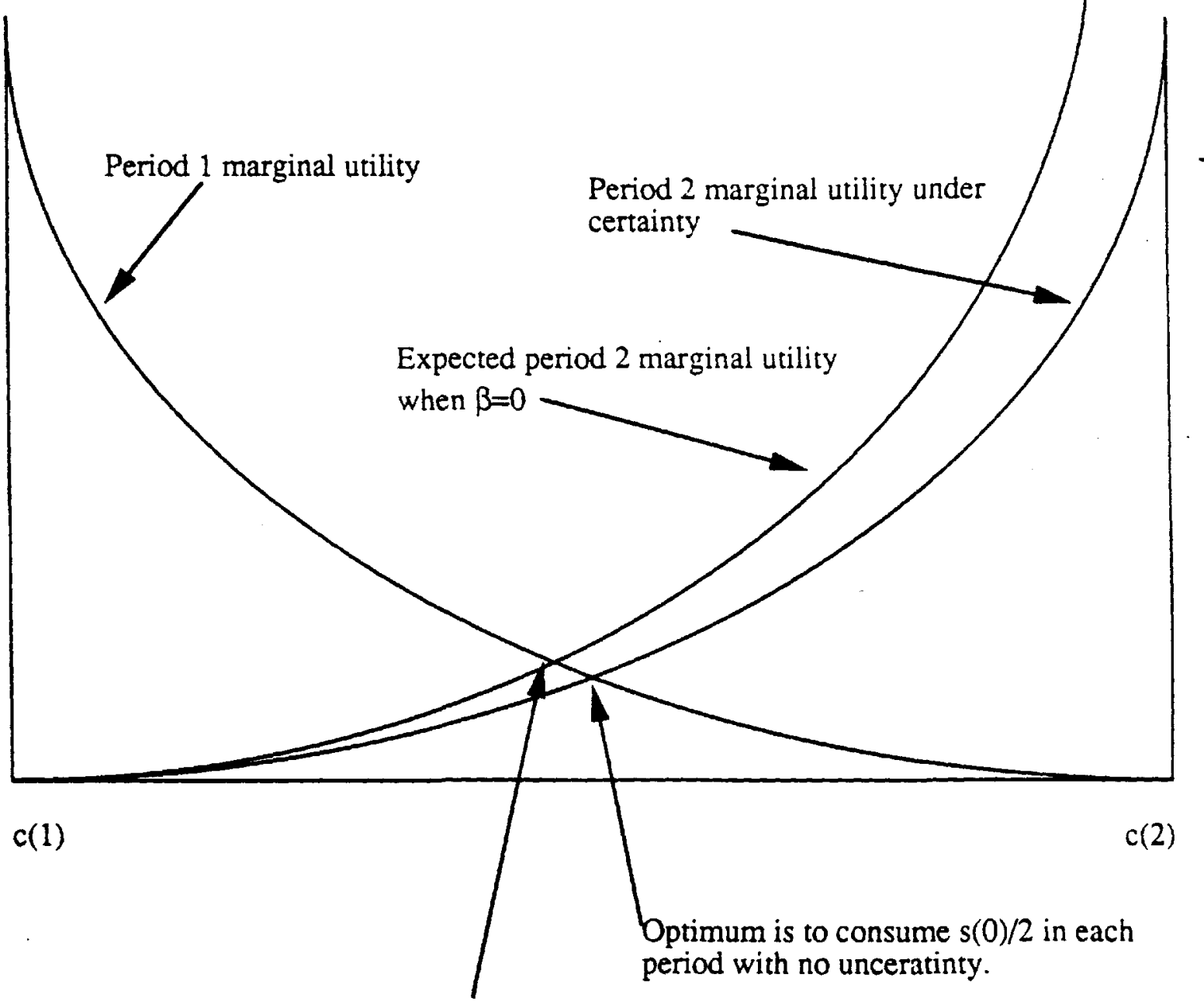

Optimum period 1 consumption is reduced if expected marginal utility in period 2 is increased. It is optimal to save for the possibility of consumption being more valuable in the future.

Figure 7: uncertainty about future preferences. 
This condition means that the expected shift in period two utility is zero. The period two expected utility curve will lie above (below) the certain curve if the left hand side of (7) is greater than (less than) unity. So if there is uncertainty about future preferences but on average we expect no net change, i.e., if an increase in preference for the resource is as likely as a decrease in the sense that (7) holds, then first and second period consumption levels will be exactly as in the certain case. Uncertainty about future preferences will not lead to a reduction in present consumption, indeed it will lead to no changes in any consumption levels, even if agents are strictly risk averse in the sense that their utility functions are strictly concave.

If on the other hand the left hand side of (7) exceeds unity, i.e., if there is an expectation of an increase in the utility of consumption in the second period, then the period two expected utility curve will lie above that under certainty and consequently the optimal period one consumption level will be lower than under certainty. Conversely, if there is an expectation of a decrease in the utility of consumption in the second period, i.e., the left hand side of (7) is less than one, then there will be a decrease in the period one consumption relative to its level under certainty.

It appears from these examples that uncertainty about future preferences alone is not sufficient to produce an "option value" type of case for increasing the resource left to the next generation. In addition to pure uncertainty, there must be asymmetry in the distribution of possible changes in preferences, with an expectation that on balance there will be an increase in the utility of consumption. Neutral uncertainty with increases and decreases equally likely, in the sense of (7), does not generate a case for leaving more to the future in case their preferences for the resource are more intense than ours. One needs the expected return to postponement of consumption to be positive, in the sense of the left hand side of (7) being positive. The same was true in the analysis of option values in the previous subsection, where the assumption of asymmetry in the returns to postponement was embodied in the inequality (5).

As a final observation and an indication of possible future research, we remark that the $\mathrm{BCH}$ model of option values which is summarized here, is one in which utility is derived only from the flow of consumption of the environmental resource. In practice the stock may enter as an argument of the utility function, in addition to the flow (as, for example, in Krautkramer [26] and in Beltratti Chichilnisky and Heal [8]). In this case there are likely to be two qualitatively different types of optimal consumption path, depending on the size of the initial stock of the resource. If this is large, the optimal path will involve the maintenance of positive stocks of the resource indefinitely: if it is small, then the entire stock will eventually be consumed. The critical initial stock at which this qualitative change occurs, will depend on preferences. In this case, it is possible that uncertainty about future preferences will tip the economy from one optimal consumption regime to another. Such a phenomenon would make a dramatic difference to the computation of the option value. 


\section{Conclusions}

The prospect of climate change induced by human activity faces societies with demanding issues in risk management and risk assessment: at the same time, it faces economics with challenges and opportunities. The challenge is to develop intellectual tools, communicate them to society at large and prove that they can add value to the analysis of a complex and possibly fundamental problem.

We have a basis for meeting this challenge. Theories of resource allocation and of decision making under uncertainty can be developed to address the specific aspects of global risk assessment and management. Uniqueness and endogeneity of risks, and irreversibility of decisions, are all phenomena which can be encompassed in extensions of our existing theories. The application to global risk management needs careful collaboration between economists and scientists. Economists need to be able to describe the set of possible outcomes, and scientists need to understand more clearly what information will help society to make informed decisions. With this information, it will be possible to design financial markets and financial instruments to allocate climate-related risks efficiently, and to modify project evaluation procedures to allow for endogeneity and irreversibility.

\section{References}

[1] Arrow, K.J. "The role of securities in an optimal allocation of risk-bearing". Econometrie, Proceedings of the Colloque sur les Fondements et Applications de la Theorie du Risque en Econometrie, Centre National de la Recherche Scientifique, Paris, 1953. English translation in Review of Economic Studies, 1964, 31 , 91-96.

[2] Arrow, K.J. and A.C. Fisher. "Environmental preservation, uncertainty and irreversibility", Quarterly Journal of Economics, 88, May 1974, 312-319.

[3] Arrow, K.J. and R.C. Lind. "Uncertainty and the evaluation of public investments". American Economic Review, 1970, 364-378.

[4] Atkinson, A.B. and J.E. Stiglitz. Lectures on Public Economics. McGraw Hill Book Company (UK) Limited, 1980.

[5] Barrett, S. Environment Directorate, OECD, Paris, 1990.

[6] Barrett, S. "The paradox of international environmental agreements". Environment Directorate, OECD, Paris, 1990.

[7] Beltratti, A., G. Chichilnisky and G.M. Heal. "Option and non-use values of environmental assets." Stanford Institute for Theoretical Economics, Technical Report No. 53, 1992. 
[8] Beltratti, A., G. Chichilnisky and G.M. Heal. "Optimal and sustainable growth paths". Working paper, Fondazione Eni Enrico Mattei, Milano.

[9] Carraro, C. and D. Siniscalco. "Strategies for international protection of the environment." Working paper, Fondazione Eni Enrico Mattei, Milano, 1991.

[10] Cass, D., G. Chichilnisky and H.M. Wu. "Individual risks and mutual insurance." CARESS Working Paper \#91-27, Department of Economics, University of Pennsylvania, 1991.

[11] Chichilnisky, G. and G. M. Heal. "Financial markets for unknown risks". First Boston Working Paper Series, Columbia Business School, 1992.

[12] Chichilnisky, G. and H.M. Wu. "Individual risk and endogenous uncertainty in incomplete asset markets". Working paper, Columbia University and Discussion Paper, Stanford Institute for Theoretical Economics, 1991.

[13] Chichilnisky G., J. Dutta and G.M. Heal. "Derivative securities and price uncertainty in a general equilibrium model." Working paper, Columbia Business School, 1991.

[14] Cichetti, C.J. and A.M. Freeman. "Option demand and consumer surplus: further comment." Quarterly Journal of Economics, 85, August 1971, 528-539.

[15] Cline, W.R. The economics of global warming. Institute for International Economics, Washington, D.C., 1992.

[16] Dasgupta, P.S. and G.M. Heal. Economic Theory and Exhaustible Resources. Cambridge Economic Handbooks, Cambridge University Press, 1979.

[17] Debreu, G. The Theory of Value. Wiley, New York.

[18] de Finetti, B. "La prevision: ses lois logiques, ses sources subjectives," Annales de l'Institute Henri Poincare, 7 1937, 1-68.

[19] Heal, G.M. "Risk management and global change". In B. Bohlin (ed) Proceedings of the First Nordic Conference on the Greenhouse Effect, 1991.

[20] Heal. G.M. "Interaction between economy and climate: a framework for policy design under uncertainty" in V.K. Smith and A.D. White (eds.) Advances in Applied Microeconomics, J.A.I. Press, 1984.

[21] Heal, G.M. "Economy and climate: a preliminary framework for microeconomic analysis" in R.E. Just and N. Bockstael (eds) Commodity and Resource Policies in Agricultural Systems, Springer, Berlin, Heidelberg and New York, 1990. 
[22] Heal, G.M. "International negotiations on emission control." Economic Development and Structural Change, 1992, Vol. 1, No. 1., pp 1-19.

[23] Heal, G.M. "Optimal resource use" in J. Sweeney (ed) Handbook of natural resource economics, North Holland Publishing Co., 1992.

[24] Henry, Cl. "Option values in the economics of irreplaceable assets". Review of Economic Studies, Symposium of the Economics of Exhaustible Resources, 1974, 89-104.

[25] Henry, Cl. "Investment decisions under uncertainty: the irreversibility effect." American Economic Review, 64, December 1974, 1005-1012..

[26] Krautkramer, J. "Optimal growth, resource amenities and the preservation of natural environments". Review of Economic Studies, LII(1) 153-170 (January 1985).

[27] Krutilla, J.V. "Conservation reconsidered". American Economic Review, 57, September 1967, 777-786.

[28] Malinvaud, E. "The allocation of individual risk in large markets". Journal of Economic Theory, 1972, 4, 312-328.

[29] Malinvaud, E. "Markets for an exchange economy with individual risk". Econometrica, 1973, 3, 383

[30] Manne, A.S. and R.G. Richels. " $\mathrm{CO}_{2}$ emission limits: an economic cost analysis for the USA". The Energy Journal, 1990, 11, No. 2.

[31] Manne, A.S. and R.G. Richels "Buying greenhouse insurance", Stanford University, mimeo, 1990.

[32] Pindyck, R.S. "Irreversibility, uncertainty and investment". Journal of Economic Literature, September 1991, Vol. XXIX, No. 3, 1110-1148.

[33] Savage, L.J. The Foundations of Statistics, Wiley, New York, 1954.

[34] Stiglitz, J.E. Ref on coinsurance \& moral hazard.

[35] Weisbrod, B.A. "Collective consumption services of individual consumption goods". Quarterly Journal of Economics, 77, August 1964, 71-77. 